DOI dx.doi.org/10.24866/7444-4707-6/154-163

М.А. Бовсун, О.В. Нестерова, В.А. Семаль, Н.А. Сакара

\title{
СОСТАВ И СВОЙСТВА БИОУГЛЯ ИЗ ВЕТULА ALBA ДЛЯ ПРИМЕНЕНИЯ НА ЗЕМЛЯХ СЕЛЬСКОХОЗЯЙСТВЕННОГО НАЗНАЧЕНИЯ В ПРИМОРСКОМ КРАЕ ${ }^{*}$
}

Общеизвестно, что интенсивное использование почв в сельском хозяйстве может привести к активизации процессов их деградации. Наряду с этим во многих регионах почвы, используемые в сельском хозяйстве, изначально обладают весьма неблагоприятными свойствами для возделывания тех или иных культур. Одним из таких регионов является Приморский край.

На территории края формируются почвы тяжелые по гранулометрическому составу и, как следствие, обладающие плохими водно-воздушными свойствами - это в сочетании с умеренным муссонным климатом приводит к частому переувлажнению поверхностных горизонтов. Поверхностное переувлажнение не является проблемой для почв в естественном залегании, однако при вовлечении их в сельское хозяйство данный вопрос становится одним из основных. Вследствие этого, агропочвы Приморского края нуждаются в мероприятиях по улучшению водно-воздушных свойств.

Одним из способов решения данной проблемы может стать внесение в почву биоугля. Биоуголь - это высокоуглеродистый и высокопористый продукт, который получают при пиролизе биомассы. Благодаря своей углеродистой высокопористой структуре он способен улучшать водоудерживающую способность и увеличивать площадь поверхности почвы (Sohi et al., 2009). Он обладает рядом физико-химических свойств, влияющих на кислотность почвы, почвенную агрегацию, доступность питательных веществ, доступность органического углерода (Lehman et al., 2015), а также способствует росту растений, увеличивает урожайность культур и уменьшает количество загрязняющих веществ (Ding et al., 2016). Тем не менее, существует множество видов биоугл, в разной степени влияющих на

\footnotetext{
* Исследование выполнено при финансовой поддержке РФФИ (№ 19-29-05166).
} 
свойства почв, поэтому перед внесением биоугля в почву следует провести ряд анализов, оценивающих его свойства.

Исходя из этого цель данной работы - оценить состав и свойства биоугля компании «Красилов и К» как потенциального структора агропочв Приморского края. В соответствии с целью были поставлены следующие задачи: оценить экологическую безопасность биоугля; оценить физико-химические характеристики биоугля по методикам IBI (IBI Biochar Standards, 2015); дать оценку потенциальной пригодности биоугля для улучшения водно-физических свойств агроземов Приморского края.

Объектом исследования является биоуголь компании «Красилов и К» (Иркутск, Российская Федерация), произведенный из древесных остатков березы Betula alba методом медленного пиролиза при температуре 360-380 ${ }^{0} \mathrm{C}$.

Для оценки качества и свойств биоугля был выбран стандарт IBI (IBI Biochar Standards, 2015). В соответствие с требованиями стандарта, были определены следующие параметры: $\mathrm{pH}$ в соответствии с методом Rajkovich et al. (2011); гигроскопическая влажность, зольность и летучие вещества методом ASTM D1762-84; размер частиц ситовым методом (сита: 0,5 мм, 1 мм, 2 мм, 4 мм, 8 мм, 16 мм, 25 мм, 50 мм).

Содержание в биоугле таких элементов как $\mathrm{C}, \mathrm{N}, \mathrm{H}$ и $\mathrm{S}$ определяли с помощью электронного CHNS анализатора PE2400 Perkin Elmer (Perkin Elmer, USA). Содержание таких элементов как $\mathrm{Ca}, \mathrm{Na}, \mathrm{Mg}, \mathrm{K}$ и др. за исключением кислорода, который был рассчитан на основе полученных данных, определяли на рентген-флуоресцентном спектрометре Shimadzu EDX-800 (Japan).

Порозность была исследована на основе снимков, сделанных на полевом эмиссионном сканирующем электронном микроскопе (FE-SEM) Sigma (Carl Zeiss, Germany). Небольшой образец биоугля помещали на медную объектив стола, покрытый двусторонним электропроводным скотчем. На скотч не наносился слой графита как в традиционной методике, из-за высокого содержания углерода в исследуемом объекте. Наблюдение проводили на ускоряющем напряжении 7кВ и вакууме $10^{-5}$ мм ртутного столба.

В результате были получены снимки с увеличением в $100 \mu \mathrm{m}, 10 \mu \mathrm{m}$ и $1 \mu \mathrm{m}$, среди которых был выбран снимок с наибольшим масштабом для расчета количества поровых пространств. Подсчет порозности был произ- 
веден в полуавтоматической программе для обработки электронных фотоснимков Smart Tiff Zeiss.

Определение водоудерживающей способности биоугля проводили согласно методике, описанной в статье Литвиновича и соавторов (2016). Для анализа было взято по 10 грамм воздушно-сухого биоугля трех разных размерностей (оригинальный биоуголь, фракция 1 мм, фракция 0,25 мм). Биоуголь помещали в химический стакан, заливали одинаковым количеством дистилированной воды и выдерживали 4 суток. Насыщенные влагой и осевшие на дно стакана частицы извлекали в воронку со смоченным до предельной влажности фильтром. Оставшиеся в стакане частички биоугля промывали одинаковым количеством дистилированной воды и также переносили на фильтр, давали стечь влаге и взвешивали фильтр с биоуглем на аналитических весах с точностью до 0,0001 г. Количество поглощенной влаги рассчитывали в процентах от массы угля в воздушносухом состоянии. Вес фильтра не учитывался и был принят как среднее значения от взвешивания пяти смоченных до предельной влажности фильтров.

При этом ряд параметров (гигроскопическая влажность, зольность, летучие вещества, полная влагоемкость) определялся с учетом оригинальной фракции биоугля и фракций, просеянных через сита 0,25 мм и 1 мм. Также в зависимости от измеряемого параметра, анализы проводились в 3-кратной и 5-кратной повторностях.

Оценка экологической безопасности биоугля для сельскохозяйственного применения была сделана на основе данных элементного анализа. В таблице 1 показан элементный состав изучаемого биоугля. Как видно, продукт содержит 4 элемента, относимых к классу опасных в соответствии со стандартом IBI. Концентрация данных элементов $(\mathrm{Cr}, \mathrm{Ni}, \mathrm{Cu}$, $\mathrm{Zn}$ ), относящихся к группе тяжелых металлов, не превышает ПДК. Так, содержание Cr 0,05 мг/кг на сухую массу не превышает 1200 мг/кг в соответствие с требованиями IBI. Подобно хрому содержание никеля, равное 0,04 мг/кг не превышает 420 мг/кг, содержание меди 0,14 мг/кг не превышает 6000 мг/кг, а содержание цинка, равное 0,57 мг/кг, не превышает 7400 мг/кг. Исходя из этого, изучаемый продукт может называться экологически чистым. 


\section{Элементный состав биоугля из Betula alba компании «Красилов и К»}

\begin{tabular}{|c|c|c|}
\hline Element & $\begin{array}{c}\text { Content, } \\
\mathrm{mg} / \mathrm{kg}\end{array}$ & $\begin{array}{c}\text { MAT IBI, } \\
\mathrm{mg} / \mathrm{kg}\end{array}$ \\
\hline $\mathrm{Ca}$ & 17,70 & - \\
\hline $\mathrm{Na}$ & 5,74 & - \\
\hline $\mathrm{Mg}$ & 4,24 & - \\
\hline $\mathrm{K}$ & 4,15 & - \\
\hline $\mathrm{Si}$ & 4,02 & - \\
\hline $\mathrm{Fe}$ & 2,35 & - \\
\hline $\mathrm{Mn}$ & 1,51 & - \\
\hline $\mathrm{Al}$ & 1,41 & - \\
\hline $\mathrm{Zn}$ & 0,57 & $416-7400$ \\
\hline $\mathrm{S}$ & 0,49 & - \\
\hline $\mathrm{Ti}$ & 0,45 & - \\
\hline $\mathrm{P}$ & 0,44 & - \\
\hline $\mathrm{Cu}$ & 0,14 & $143-6000$ \\
\hline $\mathrm{Sr}$ & 0,08 & - \\
\hline $\mathrm{Cr}$ & 0,05 & $93-1200$ \\
\hline $\mathrm{Ni}$ & 0,04 & $47-420$ \\
\hline
\end{tabular}

На основе данных элементного анализа можно провести и качественную оценку биоугля. Так, согласно проведенному анализу, исследуемый биоуголь содержит 78,13 \% углерода, 4,044 \% водорода, 0,084 \% азота и $11,342 \%$ кислорода.

На основании полученных данных исследуемый биоуголь можно назвать высококачественным, так как в соответствие со стандартом IBI все биоугли, содержащие в своем составе более 60 \% углерода, относятся к І (то есть высшему) классу биоуглей.

На основании данных элементного анализа были рассчитаны соотношения Н/С и О/С. По мнению многих авторов (Spokas, 2010; Bridgwater, 2003; Al-Wabel, 2013; Kim et. al, 2012 и др) соотношения H/C и О/С дают представление о качественности биоугля. Посчитанные в ходе данной работы соотношения $\mathrm{H} / \mathrm{C}$ и $\mathrm{O} / \mathrm{C}$ имеют значения 0,0518 и 0,1452 , соответственно. Считается, что чем ниже эти значения, тем выше качество продукта. Объяс- 
няется это тем, что низкое содержание кислорода и водорода обеспечивает более прочную связь углеродных колец, составляющих структуру биоугля, значит, чем прочнее кольца, тем медленнее будет разлагаться биоуголь (Spokas, 2010). С учетом этого, низкие значения посчитанных соотношений подтверждают высококачественность исследуемого биоугля.

Исследуемый биоуголь имеет значение $\mathrm{pH}$, равное 8,09, то есть имеет слабощелочную реакцию среды. Многими авторами отмечается (Григорьян, 2016; Al-Wabel, 2013; Godlwska et. al, 2017; Литвинович, 2016 и др), что внесение биоугля в почву ведет к ее подщелачиванию, что может оказаться благоприятным для культурных растений, выращиваемых в зоне кислых почв. Например, в статье Ванга и соавторов в результате применения биоугля из рисовой шелухи почвенная кислотность уменьшилась с 3.33 до 3.63 (Wang et al. 2014), а в статье Леирда с соавторами при использовании биоугля, полученного из смеси древесных пород (дуба и гикори), почвенное рН увеличилось почти на еденицу (Laird et al. 2010). Исходя из этого, можно предполагать, что применение биоугля на кислых и слабокислых почвах Приморского края увеличит значения рН до необходимых показателей.

Химические параметры - зольность и летучие соединения - характеризуют процент зольных и летучих элементов, содержащихся в биоугле. Количество зольных элементов биоугля соответствует количеству зольных элементов в исходной биомассе, а количество летучих веществ может отражать их содержание, как в исходной биомассе, так и увеличение их количества при производстве. Показатели зольности и летучих соединений различны для разных типов биоуглей. Древесные биоугли обычно содержат небольшое количество золы, несколько процентов (Ronsse et al., 2012; Kim et al, 2012), в то время как другие виды биоугля могут содержать и значительно большее количество золы (Al-Wabel, 2013, Novotny et al., 2015; Wang et. al, 2018; Shah et al. 2012), иногда их зольность может достигать $41 \%$ (Raymond, 2013). Значения зольности изучаемого биоугля колеблются в пределах от 4,1 \% до 6,4 \% в зависимости от размера фракции биоугля, а значения летучих элементов в пределах от 23,5 \% до 26,9 \% (табл. 2). Как видно из таблицы 2, наименьшие значения зольности и летучих соединений имеет биоуголь в естественном виде, это вероятно, объясняется наличием большего количества макропор (пор размером более $50 \mu \mathrm{m})$, то есть большего количества пустого пространства, чем во фрак- 
циях в 1 мм и 0,25 мм. По сравнению с исследованиями других авторов данные показатели можно охарактеризовать как средние, что хорошо, поскольку высокое содержание золы и летучих соединений может вызывать затруднение проходимости пор биоугля и, следовательно, уменьшать площадь его поверхности и сорбционную способность (Taha et al., 2014).

Согласно проведенному расчету порозности, биоуголь на участке площадью 0,41 мм² содержит 963 поры, 97 \% (934 поры) которых приходится на мезопоры размером от 2 до $50 \mu \mathrm{m}(0,002-0,05$ мм), а $3 \%$ (29 пор) - на макропоры размером более $50 \mu \mathrm{m}$. По утверждению И.Р. Мухиной, наличие в биоугле большого количества микро- и мезопор характеризует его высокую внутреннюю удельную поверхность (Мухина, 2017), о данном факт утверждают и Й. Лехманом с С. Джозефом (Lehmann, 2009), которые также считают, что с увеличением количества микро- и мезопор, и соответственно, с увеличением внутренней удельной поверхности биоугля, уменьшается подвижность почвенной воды. Макропоры способствуют доступности адсорбентов к внутренней поверхности биоугля и усиливают межфазные взаимодействия (Мухина, 2017).

Таблица 2

Содержание зольных и летучих элементов в биоугле из Betula alba компании «Красилов и К»

\begin{tabular}{|l|l|l|l|}
\hline \multirow{2}{*}{ Parameter } & \multicolumn{3}{|c|}{ Fraction } \\
\cline { 2 - 4 } & original & $1 \mathrm{~mm}$ & $0,25 \mathrm{~mm}$ \\
\hline Ash, \% dry weight & 4,1 & 5,5 & 6,4 \\
\hline $\begin{array}{l}\text { Volatile matter, \% } \\
\text { dry weight }\end{array}$ & 23,5 & 26,7 & 26,9 \\
\hline
\end{tabular}

Чтобы наглядно убедиться в высоком значении порозности, можно произвести сравнительную характеристику биоугля с углями, существующими в природе. Так в в качестве объектов для сравнения было взято два вида углей: каменный уголь Липовецкого угольного разреза (п. Липовцы, Приморский край, Российская Федерация) и бурый уголь Лучегорского угольного разреза (п. Лучегорск, Приморский край, Российская Федерация). На снимках углей при разном увеличении, сделанные при помощи электронного микроскопа не нужно даже присматриваться, чтобы увидеть особую пористую структуру биоугля, существенно отличающуюся от структуры каменного и 
бурого углей. Такая особая высокопористая структура определяет не только величину площади удельной поверхности биоугля и скорость межфазных взаимодействий, но и благоприятно влияет на жизнедеятельность микроорганизмов и микоризных грибов. Дело в том, что в поровых пространства биоугля создаются оптимальные условия для их жизнедеятельности, в которых они чувствуют себя в полной безопасности и начинают активно расти и размножаться (Мухина, 2017). По данным некоторых авторов (Григорьян, 2016; Орлова, 2017), внесение биоугля в отдельных случаях может увеличивать количество микроорганизмов в 2, 3 и даже в 5 раз. В результате этого могут существенно ускоряться процессы гумификации и развитие ризосферы, что влечет за собой улучшение роста и развития растений.

Высокая порозность биоугля обеспечивает ему высокие сорбционные свойства. Биоуголь способен поглощать воду, масса которой превышает его собственный вес. Отдельные фракции биоугля способны поглощать воду массой в 3 раза превышающую вес биоугля. Так, в работе Литвиновича и соавторов в ходе проведенных испытаний было показано, что фракция биоугля размером менее 2 мм может поглощать $285 \%$ воды, фракция 2-3 мм - 250 \% воды, а фракция 3-5 мм - 198\%. (А.В. Литвинович, 2016). Проведенные тесты в ходе работы показали (табл. 3), что наибольшее количество влаги способна удерживать фракция размером 1 мм (242\%), а минимальное - оригинальный биоуголь (110\%).

Таблица 3

Характеристика полной влагоемкости и коэффициента увлажнения биоугля из Betula alba компании «Красилов и К»

\begin{tabular}{|c|c|}
\hline Фракция, мм & $\begin{array}{c}\text { Полная } \\
\text { влагоемкость, \% }\end{array}$ \\
\hline Оригинальный биоуголь & 110 \\
\hline Частицы биоугля размером 1 мм & 242 \\
\hline $\begin{array}{c}\text { Частицы биоугля } \\
\text { размером 0,25 мм }\end{array}$ & 183 \\
\hline
\end{tabular}

Фракция размером 0,25 мм имеет значение полной влагоемкости равное $183 \%$. Важно также отметить, что фракция в 1 мм является и наиболее гигроскопичной, а значит, в воздушно-сухом состоянии содержит больше влаги, чем другие фракции. Сравнивая результаты данной ра- 
боты и работы Литвиновича с соавторами, можно заключить, что наиболее сорбционноспособной является фракция в 1-2 мм. Логично заключить, что с целью максимального поглощения влаги, в почву необходимо вносить биоуголь данного размера.

По результатам гранулометрического анализа в изучаемом биоугле на фракцию 1-2 мм приходится всего 7,1 \% от всей массы. Небольшое процентное содержание данной фракции обусловлено методом производства. Согласно исследованию А. Дауни, с увеличением температуры и времени производства увеличивается процентное содержание мелких фракций биоугля (Downie, 2011). Исследуемый биоуголь был получен путем медленного пиролиза биомассы при температуре $360-380{ }^{\circ} \mathrm{C}$, именно поэтому он содержит небольшое количество фракции в 1-2 мм, а его большая часть приходится на фракции 8-16 мм (36,6 \%), 16-25 мм (13,8 \%) и 4-8 мм (14,4 \%). В сумме на 3 данные фракции приходится 64,8 \%, что соответствует примерно двум третьим части биоугля. Учитывая преобладание в составе биоугля фракций размером от 4 до 25 мм и небольшое содержание наиболее реакционно способной фракции в 1-2 мм, исследуемый биоуголь, для максимального улучшения свойств почвы, перед внесением необходимо измельчить до размера в 1-2 мм.

Определенные значения химических, физических и физикохимических параметров исследуемого биоугля соответствуют всем требованиям стандарта IBI и указывают на то, что исследуемый биоуголь - это высококачественный, имеющий прочную высокопористую структуру и хорошие сорбционные свойства продукт с большим процентным содержанием углерода (78\%) и низкими соотношениями $\mathrm{H} / \mathrm{C}$ и O/C.

Применение данного биоугля на почвах Приморского края может дать положительный результат главным образом в аспекте улучшения водно-физических свойств почв.

\section{Литература}

1. Al-Wabel, M. I. Pyrolysis temperature induced changes in characteristics and chemical composition of biochar produced from conocarpus wastes / M. I. Al-Wabel, A. Al-Omran, A. H. El-Naggar, M. Nadeem, A. R. A. Usman // Bioresuors Technology. - 2013. - № 131. - P. 374-379.

2. Bridgwater, A. V. Renewable fuels and chemicals by thermal processing of biomass // Chem. Eng. Journal. - 2003. - Vol.91. - P. 87-102. 
3. Ding, Y. Biochar to improve soil fertility. A review / Y. Ding, Y. Liu, S. Liu, Z. Li, X. Tan, X. Huang, G. Zeng, L. Zhou, B. Zheng // Agron. Sustain. Dev. - 2016. -18 p.

4. Downie, A. Biochar production and use: environmental risks and rewards / A. Downie. - The University of New South Wales, 2011. - 308 p.

5. Goalewska, P Biochar for composting improvement and contaminants reduction. A review / P. Godlewska, H. P. Scymidt, Y. S. Ok, P. Oleszczuk // Bioresource Technoogy. - 2017. - № 246. - P. 193-202.

6. Kim, K. H. Influence of pyrolysis temperature on physicochemical properties of biochar obtained from the fast pyrolysis of pitch pine (Pinus rigida) / K. H. Kim, J-Y. Kim, T-S. Cho, J. W. Choi // Bioresource Technology. - 2012. № 118 . - P. 158-162.

7. Laird, D. A. Impact of biochar amendments on the quality of a typical Midwestern agricultural soil / D. A. Laird, P. Fleming, D. D. Davis, R. Horton, B. Wang, D. L. Karlen // Geoderma. - 2010. - № 158. - P. 443-449.

8. Lehmann, J. Biochar and the plant-soil interface / J. Lehmann, Y. Kuzyakov, G. Pan, Y. S. Ok // Plant Soil. - 2015. - Vol. 395. - P. 1-5.

9. Lehmann, J. Biochar for environmental management: Biochar Effects on Soil Nutrient Transformations / J. Lehmann, S. Joseph // Earthscan. - 2009. P. 251-265.

10. Novotny, E. H. Biochar: Pyrogenic Carbo For Agricultural Use A Critical Review / E. H. Novotny, C. M. B. de Freitas Maia, M. T. de Melo Carvalho, B. E. Madari // R. Bras. Ci. Solo. - 2015. - Vol. 39. - P. 321-344.

11. Rajkovich, S. Corn growth and nitrogen nutrition after additions of biochars with varying properties to a temperate soil / S. Rajkovich, A. Enders, K. Hanley, C. Hyland, A. R. Zimmerman, J. Lehmann // Biol. Fertil. Soils. 2011.

12. Raymond, S. Slow Pyrolysis of maize stover for biochar production / S. Raymond. - Kwame Nkrumah University of Science and Technology, 2013. - 79 p.

13. Ronsse, F. Production and characterization of slow pyrolysis biochar: influence of feedstock type and pyrolysis conditions / F. Ronsse, S. van Hecke, D. Dickinson, W. Prins // Global Change Biology Bioenergy. - 2012. - Vol. 5. - i. 2. P. 104-115.

14. Shah, A. Physicochemical properties of bio-oil and biochar produced by fast pyrolysis of stored single-pass corn stover and cobs / A. Shah, M. J. 
Darr, D. Dalluge, D. Medic, K. Webster, R. C. Brown // Bioresource Technology. - 2012. - № 125. - P. 348-352.

15. Sohi, S. Biochar, climate change and soil: A review to guide future research / S. Sohi, E. Lopez-Capel, E. Krull, R. Bol // CSIRO Land and Water Science Report, 2009. - 57 p.

16. Spokas, K. A. Review of the stability of biochar in soils: predictability of O:C molar ratios // Carbon Manage. - 2010. - Vol.1. - P. 289-303.

17. Taha, S.M. Adsorption of different pesticides on untreated and phosphoric acid treated biochar and charcoal from water / S.M. Taha, M.E. Amer, A.E. Elmarsafy, M.Y. Elkady // J. Environ Chem. - 2014.

18. Wang, H. Slow pyrolysis polygeneration of bamboo (Phyllostachys pubescens): Product yield prediction and biochar formation mechanism / $\mathrm{H}$. Wang, X. Wang, Y. Gui, Z. Xue, Y. Ba // Bioresource Technology. - 2018. № 263. - P. 444-449.

19. Wang, Y. Characterization of biochar from fast pyrolysis and its effect on chemical properties of the tea garden soil / Y. Wang, R. Yin, R. Liu // J. Anal. Appl. Pyrol. - 2014. - № 110. - P. 375-381.

20. Библиографическая ссылка: Standard Test Method for Chemical Analysis of Wood Charcoal: ASTM D1762-84. - Введ. 04.2007. - 2 p.

21. Библиографическая ссылка: Product Definition and Specification Standards: Standardized Product Definition and Product Testing Guidelines for Biochar That Is Used in Soil (aka IBI Biochar Standards) Version 2.1. - Введ. 23.11.2015. - IBI, 2015. - 61 p.

22. Григорьян, Б. Р. Влияние биоугля на рост растений, микробиологические и физико-химические показатели мало гумусированной почвы в условиях вегетационного опыта / Б. Р. Григорьян, А. Н. Грачев, В. И. Кулагина, Л. М. Сунгатуллина, Т. Г. Кольцова, С. С. Рязанов // Вестник технологического университета. - 2016. - № 11. - С. 185-189.

23. Литвинович, А. В. Эмпирические модели водоудерживающей способности песчаной почвы, мелиорируемой различными по размеру фракциями биоугля / А. В. Литвинович, А. А. М. Хаммам, В. М. Буре // Агрономия. Ветеринария и зоотехния. - 2016. - С. 107-113.

24. Мухина, И. М Влияние карбонизированной биомассы на параметры плодородия дерново-подзолистых почв и эмиссию парниковых газов / И. М. Мухина. - Санкт-Петербург, 2017. - 187 с. 